\title{
Comparison and Evaluation of Force Fields for Intrinsically Disordered Proteins
}

\author{
Mueed Ur Rahman ${ }^{1}$, Ashfaq Ur Rehman ${ }^{1}$, Hao Liu ${ }^{1}$ and Hai-Feng Chen ${ }^{1,2 *}$ \\ ${ }^{1}$ State Key Laboratory of Microbial metabolism, Joint International Research Laboratory of \\ Metabolic \& Developmental Sciences, Department of Bioinformatics and Biostatistics, \\ National Experimental Teaching Center for Life Sciences and Biotechnology, School of Life \\ Sciences and Biotechnology, Shanghai Jiao Tong University, Shanghai, 200240, China \\ ${ }^{2}$ Shanghai Center for Bioinformation Technology, Shanghai, 200235, China
}

\section{Corresponding Author}

Hai-Feng Chen (Full Professor)

State Key Laboratory of Microbial metabolism, Joint International Research Laboratory of Metabolic \& Developmental Sciences, Department of Bioinformatics and Biostatistics, National Experimental Teaching Center for Life Sciences and Biotechnology, School of Life Sciences and Biotechnology, Shanghai Jiao Tong University, Shanghai, 200240, China Tel: 86-21-34204348; Fax: 86-21-34204348; Email: haifengchen@sjtu.edu.cn

\section{Notes}

1 The authors declare no competing financial interest. 
22 Table S1. Predicetd measurements comparison

\begin{tabular}{|c|c|c|c|c|c|c|c|}
\hline Atom & $\begin{array}{l}\text { Proteins } \\
\text { /peptide } \\
\quad \text { s }\end{array}$ & $\begin{array}{c}f f 99 I D \\
\text { Ps }\end{array}$ & $\begin{array}{c}f f 14 I \\
\text { DPs }\end{array}$ & $\begin{array}{c}f f 14 I D P S \\
\text { FF }\end{array}$ & ff03w & c36m & $\mathrm{C} 22 *$ \\
\hline \multirow{10}{*}{ ư } & & \multicolumn{6}{|c|}{$\Delta \mathrm{RMSD}(\mathrm{ppm})$} \\
\hline & $\begin{array}{l}\text { RS- } \\
\text { peptide }\end{array}$ & 0.01 & $(0.28)$ & $(0.28)$ & 0.23 & 1.59 & 0.92 \\
\hline & $\begin{array}{l}\text { HEWL1 } \\
9\end{array}$ & 0.4 & $(0.75)$ & 0.43 & 1.16 & 1.18 & 0.88 \\
\hline & HIV-rev & $(0.51)$ & 0.09 & 0.1 & 0.53 & 0.97 & 0.28 \\
\hline & $\mathrm{A} \beta 40$ & 0.08 & $(0.39)$ & 0.07 & 0.43 & 0.06 & 0.16 \\
\hline & $\begin{array}{l}\mathrm{A} \beta 42^{\text {mode }} \\
1\end{array}$ & 0.04 & 0.16 & 0.14 & 0.32 & $(0.42)$ & $(0.42)$ \\
\hline & $\mathrm{A} \beta 42^{1 \mathrm{Z} 0 \mathrm{Q}}$ & $(0.45)$ & 0.16 & 0.13 & 0.6 & 0.65 & 0.11 \\
\hline & $\mathrm{pdE}-\gamma$ & $(0.53)$ & 0.1 & 0.06 & 0.07 & 0.15 & 0.09 \\
\hline & $\begin{array}{l}\text { CspTm } \\
\text { (folded) }\end{array}$ & 0.07 & 0.01 & 0.06 & 0.13 & 0.09 & $(0.79)$ \\
\hline & $\begin{array}{l}\text { Ubiquiti } \\
\mathrm{n} \\
\text { (folded) }\end{array}$ & 0.05 & 0.03 & 0.01 & 0.05 & 0.05 & 0.05 \\
\hline \multirow{7}{*}{ u் } & HIV-rev & 0.09 & 0.15 & 0.04 & $(0.33)$ & 0.08 & 0.06 \\
\hline & $\mathrm{A} \beta 40$ & 0.19 & $(0.47)$ & 0.01 & 0.19 & 0.05 & 0.04 \\
\hline & ${ }_{1}^{\mathrm{A}} \beta 42^{\text {mode }}$ & 0.27 & 0.08 & $(0.39)$ & 0.32 & 0.09 & 0.01 \\
\hline & $\mathrm{A} \beta 42^{1 \mathrm{Z} 0 \mathrm{Q}}$ & 0.17 & 0.01 & 0.07 & 0.31 & 0.06 & $(0.48)$ \\
\hline & $\mathrm{pdE}-\gamma$ & 0.19 & $(0.55)$ & 0.05 & 0.24 & 0.05 & 0.09 \\
\hline & $\begin{array}{l}\text { CspTm } \\
\text { (folded) }\end{array}$ & 0.05 & $(0.95)$ & 0.02 & 0.28 & 0.05 & $(0.95)$ \\
\hline & $\begin{array}{l}\text { Ubiquiti } \\
\mathrm{n} \\
\text { (folded) }\end{array}$ & 0.07 & 0.05 & $(0.67)$ & 0.03 & 0.08 & 0.16 \\
\hline \multirow{7}{*}{ 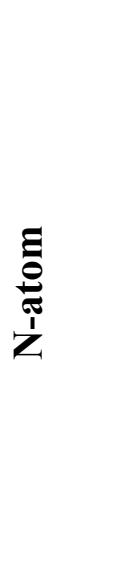 } & $\begin{array}{l}\text { HEWL1 } \\
9\end{array}$ & 0.58 & $(0.8)$ & 0.12 & 0.8 & 0.48 & 0.36 \\
\hline & HIV-rev & $(0.85)$ & $(0.85)$ & 0.6 & 1.12 & 1.3 & 1.17 \\
\hline & $\mathrm{A} \beta 40$ & 0.69 & 0.2 & $(1.8)$ & 1.14 & 0.03 & 0.18 \\
\hline & $\begin{array}{l}\mathrm{A} \beta 42^{\text {mode }} \\
1\end{array}$ & 1.03 & 0.35 & 0.32 & 1.2 & $(1.15)$ & 0.2 \\
\hline & $\mathrm{A} \beta 42^{1 \mathrm{Z} 0 \mathrm{Q}}$ & 0.66 & 0.2 & 0.37 & 0.78 & (1.96) & 0.14 \\
\hline & $\mathrm{pdE}-\gamma$ & 0.5 & $(1.5)$ & 0.1 & 0.63 & 0.05 & 0.44 \\
\hline & $\begin{array}{l}\text { CspTm } \\
\text { (folded) }\end{array}$ & 0.35 & $(2.07)$ & 0.21 & 0.73 & 0.75 & 0.34 \\
\hline
\end{tabular}




\begin{tabular}{|c|c|c|c|c|c|c|c|}
\hline & $\begin{array}{l}\text { Ubiquiti } \\
\mathrm{n} \\
\text { (folded) }\end{array}$ & 0.12 & 0.08 & 0.01 & 0.09 & $(1.83)$ & 0.17 \\
\hline \multirow{8}{*}{ 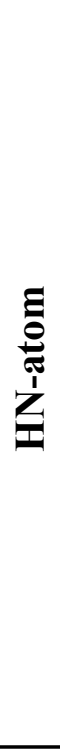 } & $\begin{array}{l}\text { HEWL1 } \\
9\end{array}$ & 0.12 & $(0.18)$ & 0.06 & 0.16 & 0.21 & 0.21 \\
\hline & HIV-rev & 0.05 & $(0.17)$ & 0.07 & 0.15 & 0.17 & 0.24 \\
\hline & $\mathrm{A} \beta 40$ & 0.06 & 0.03 & 0.04 & 0.18 & $(0.22)$ & 0.04 \\
\hline & ${ }_{1}^{\mathrm{A}} \beta 42^{\text {mode }}$ & 0.04 & 0.03 & 0.02 & 0.1 & 0.01 & 0.18 \\
\hline & $\mathrm{A} \beta 42^{1 \mathrm{ZOQ}}$ & 0.05 & 0.03 & 0.03 & 0.14 & $(0.2)$ & 0.03 \\
\hline & $\mathrm{pdE}-\gamma$ & 0.01 & $(0.22)$ & $(0.22)$ & 0.05 & 0.01 & 0.06 \\
\hline & $\begin{array}{l}\text { CspTm } \\
\text { (folded) }\end{array}$ & 0.08 & 0.04 & 0.04 & 0.08 & 0.09 & 0.04 \\
\hline & $\begin{array}{l}\text { Ubiquiti } \\
\mathrm{n} \\
\text { (folded) }\end{array}$ & 0.02 & 0.02 & 0.01 & 0.03 & $(0.28)$ & 0.02 \\
\hline \multirow{4}{*}{ 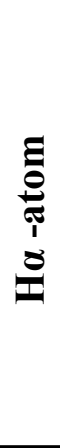 } & $\begin{array}{l}\text { HEWL1 } \\
9\end{array}$ & 0.02 & $(0.17)$ & 0.03 & 0.06 & 0.05 & 0.03 \\
\hline & HIV-rev & $(0.09)$ & 0.01 & 0.01 & 0.02 & 0.03 & 0.02 \\
\hline & $\begin{array}{l}\text { CspTm } \\
\text { (folded) }\end{array}$ & 0.01 & $(0.22)$ & $(0.22)$ & 0.03 & 0.06 & 0.04 \\
\hline & $\begin{array}{l}\text { Ubiquiti } \\
\mathrm{n} \\
\text { (folded) }\end{array}$ & $(0.08)$ & $(0.08)$ & $(0.08)$ & 0.01 & 0.01 & 0.01 \\
\hline \multirow{7}{*}{$\underset{⿱ ⺌}{\frac{1}{n}}$} & & \multicolumn{6}{|c|}{$\Delta \mathrm{RMSD}(\mathrm{HZ})$} \\
\hline & $\begin{array}{l}\text { RS- } \\
\text { peptide }\end{array}$ & $(0.54)$ & 0.24 & 0.02 & 0.6 & 1.51 & 0.41 \\
\hline & HIV-rev & $(0.94)$ & 0.1 & 0.14 & 0.73 & 1.51 & 0.02 \\
\hline & $\mathrm{A} \beta 40$ & $(0.65)$ & 0.45 & 0.13 & 0.45 & 0.18 & 0.18 \\
\hline & ${ }_{1}^{\mathrm{A}} \beta 42^{\text {mode }}$ & $(0.66)$ & 0.06 & 0.15 & 0.11 & 0.06 & 0.1 \\
\hline & $\mathrm{A} \beta 42^{1 \mathrm{ZOQ}}$ & $(0.7)$ & 0.27 & 0.31 & 0.35 & 0.68 & 0.25 \\
\hline & $\begin{array}{l}\text { Ubiquiti } \\
\mathrm{n} \\
\text { (folded) }\end{array}$ & $(0.92)$ & 0.08 & 0.06 & 0.36 & 0.11 & 0.03 \\
\hline \multirow{2}{*}{$\frac{\text { O্் }}{\frac{1}{n}}$} & $\mathrm{~A} \beta 40$ & $(0.36)$ & 0.03 & 0.06 & 0.61 & 0.05 & 0.24 \\
\hline & $\begin{array}{l}\text { Ubiquiti } \\
\mathrm{n} \\
\text { (folded) }\end{array}$ & 0.05 & 0.03 & $(0.28)$ & 0.15 & 0.04 & 0.08 \\
\hline
\end{tabular}


23 All of the reported differences in RMSD values ( $\triangle$ RMSD) are calculated between the 24 lowest RMSDs (given in parenthesis) and any other RMSDs (anyRMSD - lowestRMSD, 25 calculated between the predicted obsevables and NMR experiment). Lowest RMSDs 26 under the given force field indicates the closer simulated value with experiment.

27

28

29 

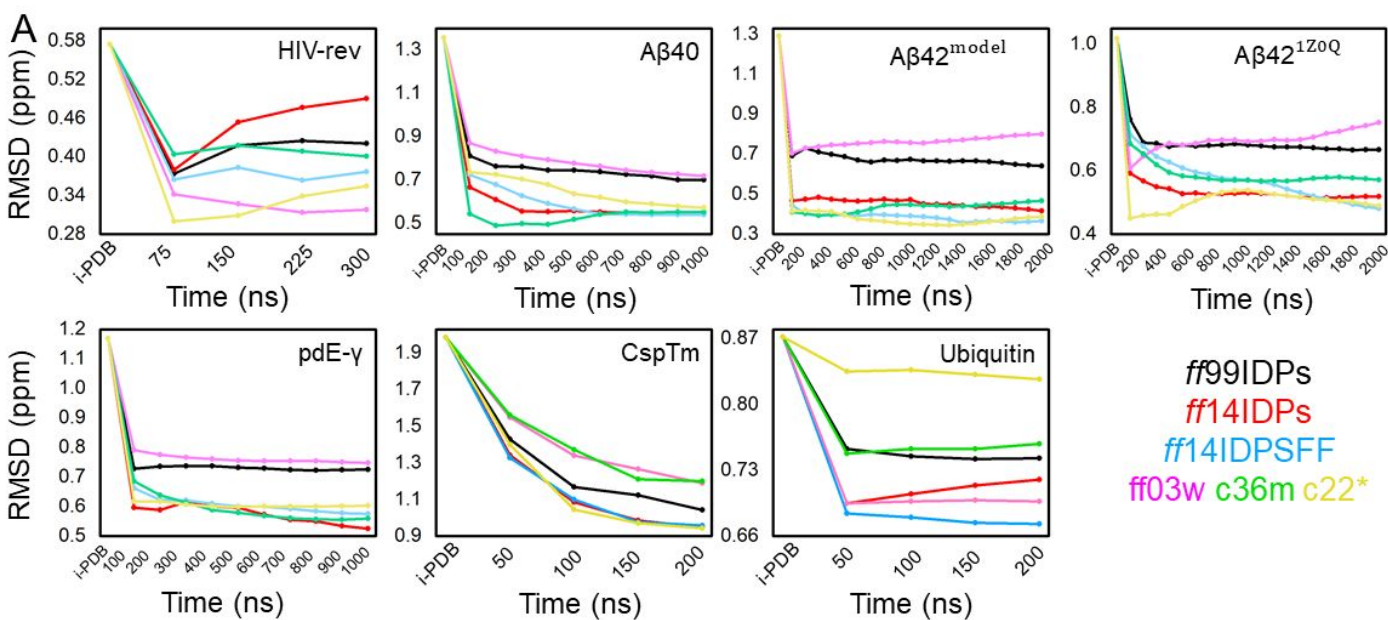

Time (ns)

Time (ns)

ff99IDPs ff14IDPs ff14IDPSFF ff03w c36m c22*
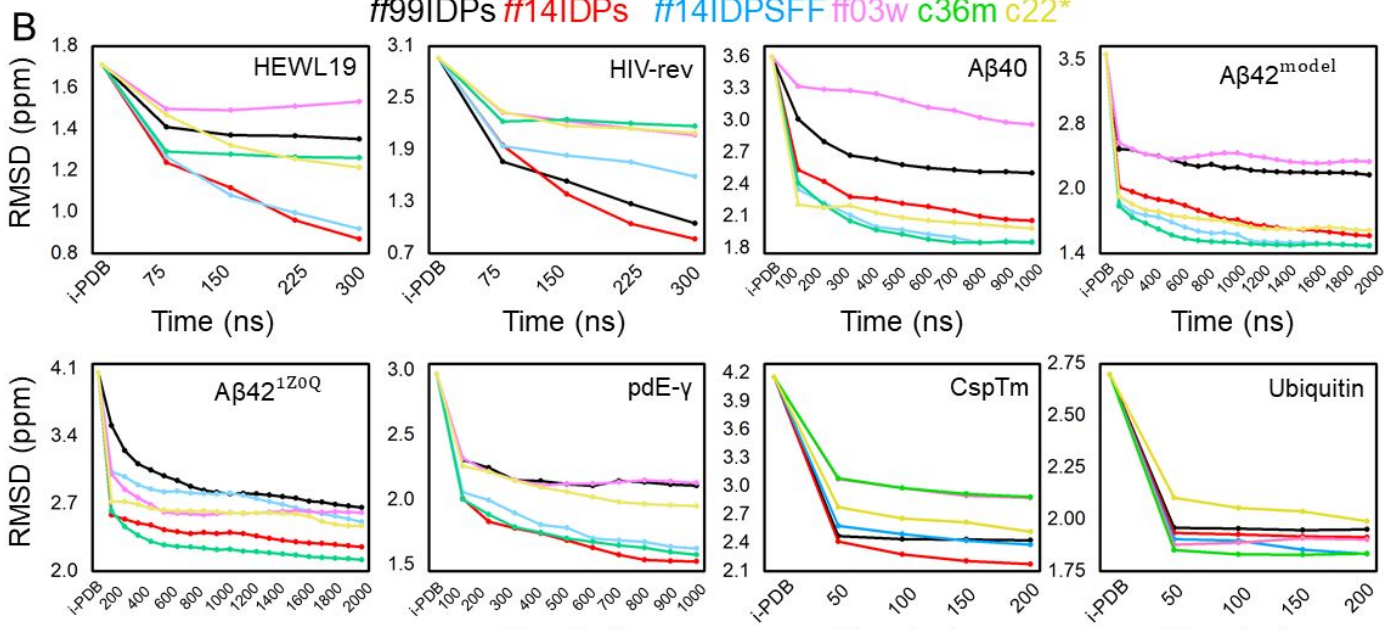

Time (ns)

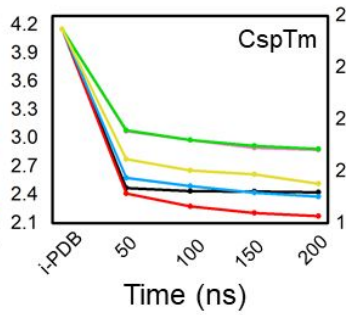

ff99IDPs

ff14IDPs

ff14IDPSFF

ff03w c36m c22*

31

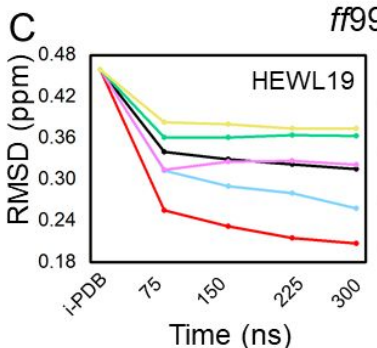

ff99IDPs ff14IDPs ff14IDPSFF ff03w c $36 \mathrm{~m} \mathrm{c22*}$
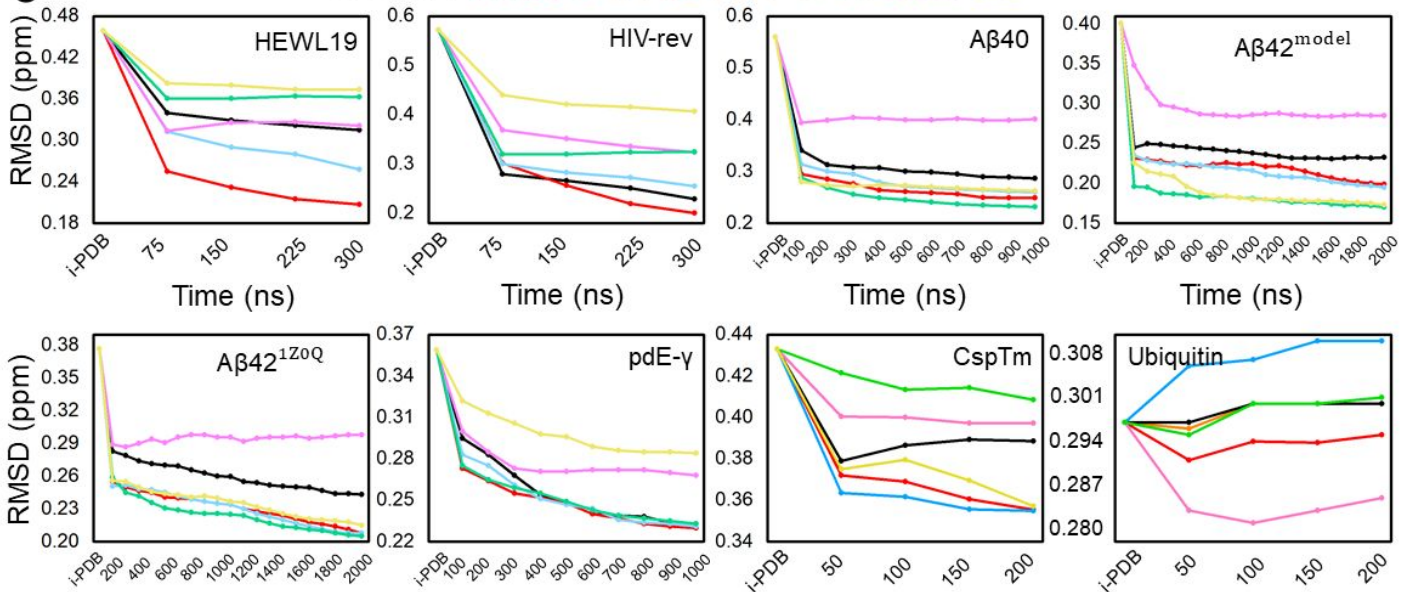

Time (ns)

Time (ns)

Time (ns)
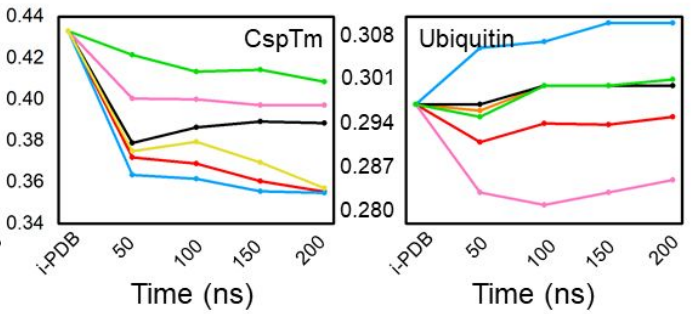


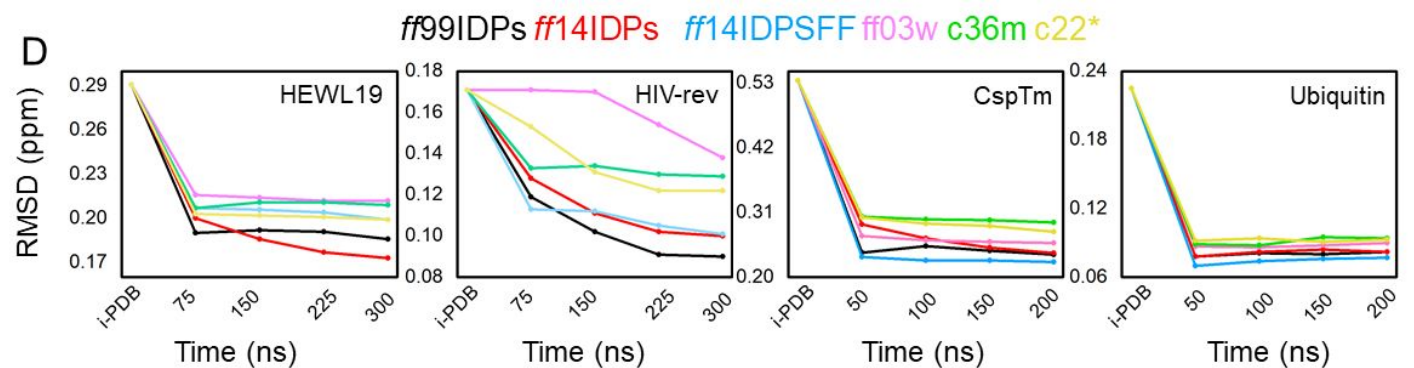

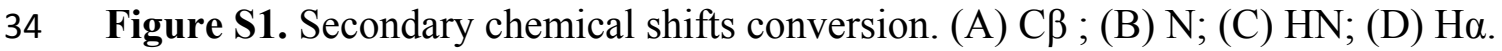
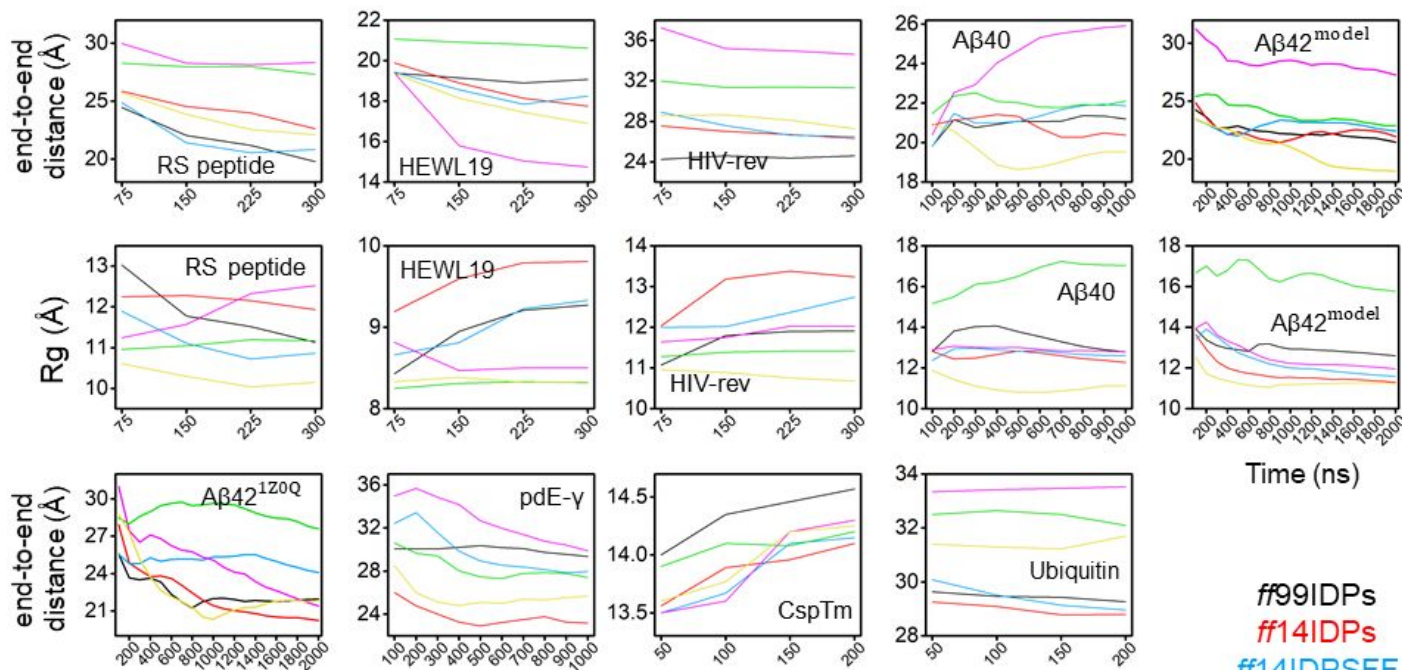

Time (ns)
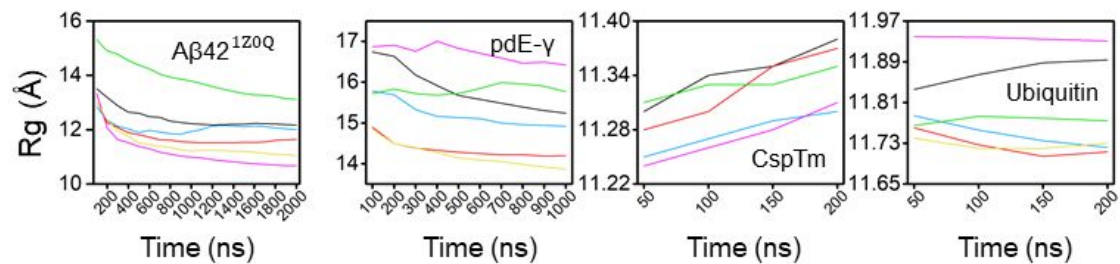

ff99।DPs

ff14IDPs

ff14IDPSFF

Figure S2. Time evolution of cumulative $\mathrm{Rg}$ and end-to-end distance. The end-to-end distance were calculated using $\mathrm{C} \alpha$ atom of end residues. 

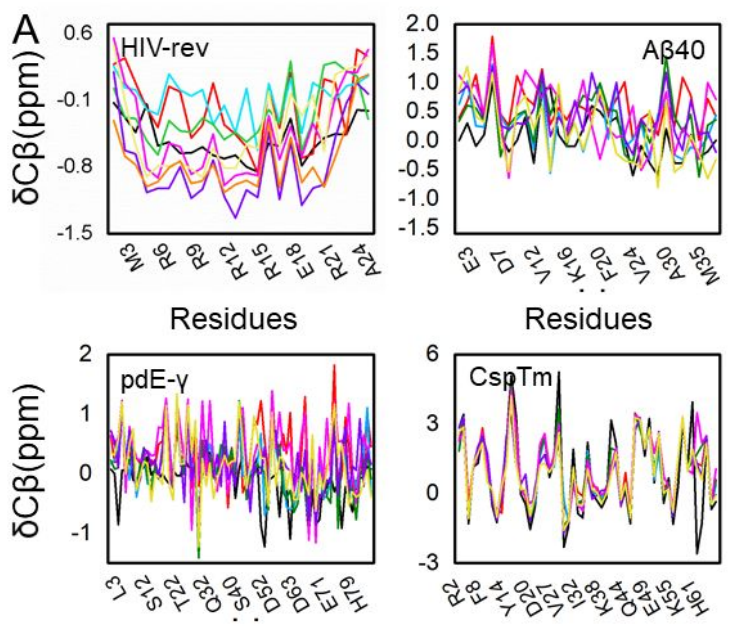

41

Residues
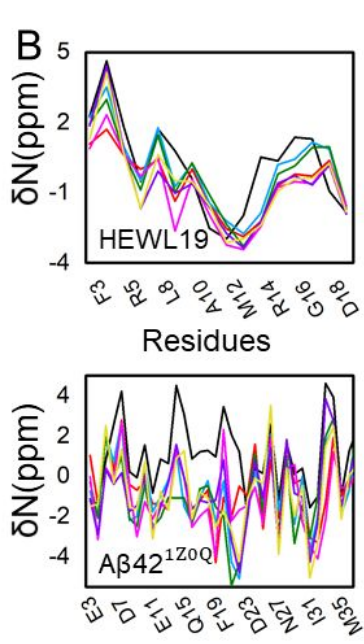

42
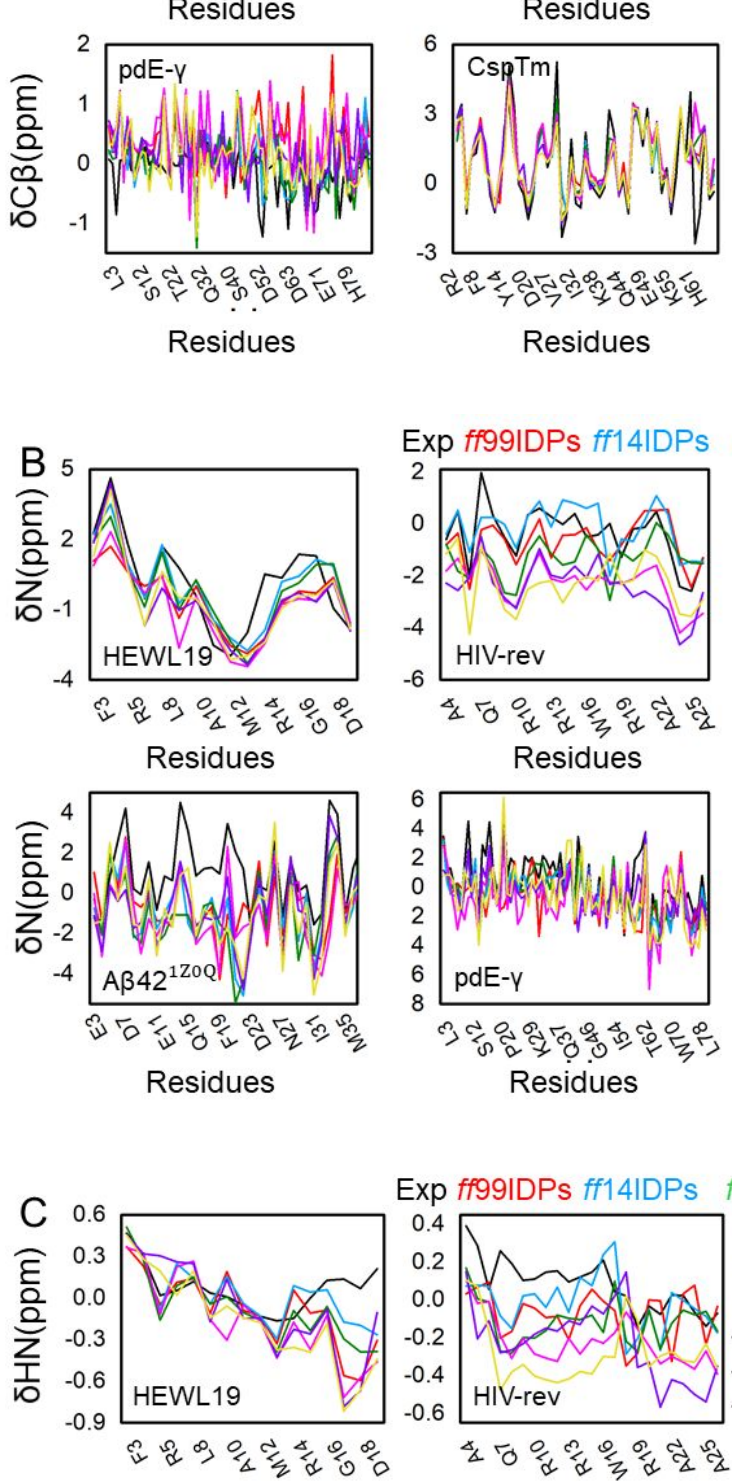

Residues
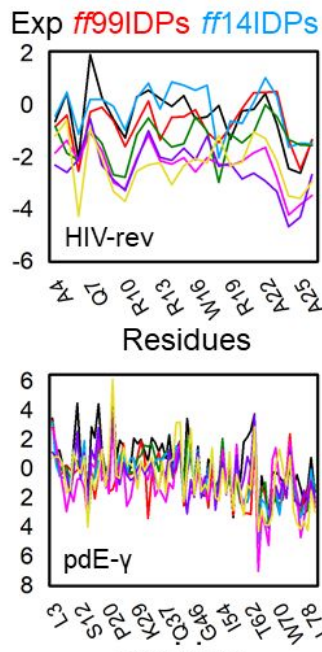

Residues

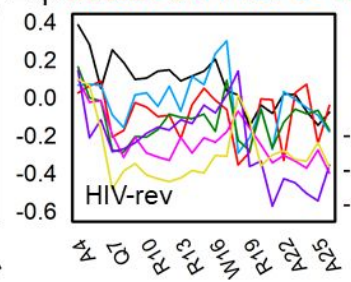

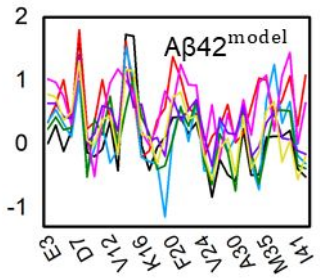

Residues

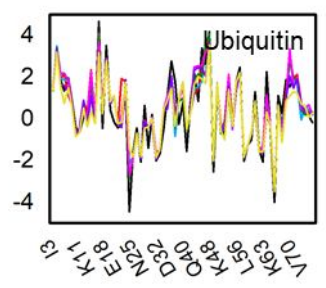

Residues

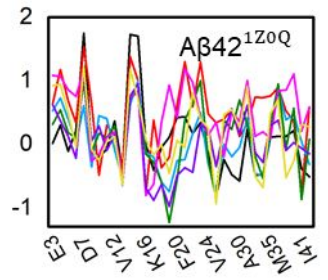

Residues

Exp ff99IDPs ff14IDPs ff14IDPSFF

ff03w c36m c22*

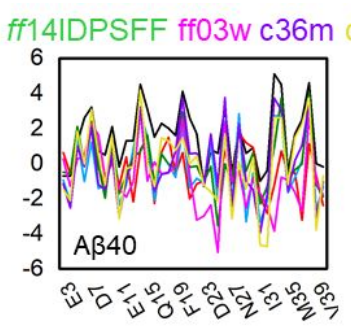

Residues

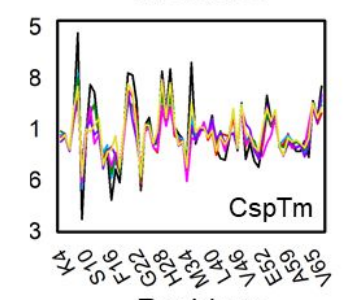

Residues

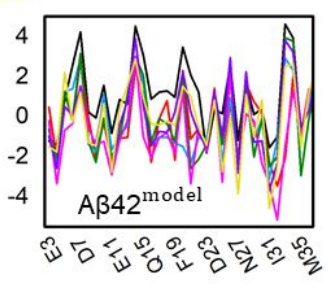

Residues

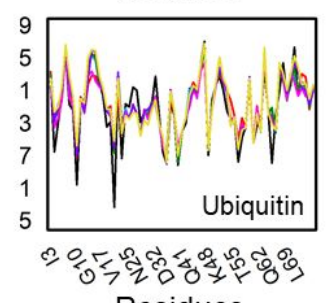

Residues

Exp ff99IDPs ff14IDPs ff14IDPSFF ff03w c36m c22*
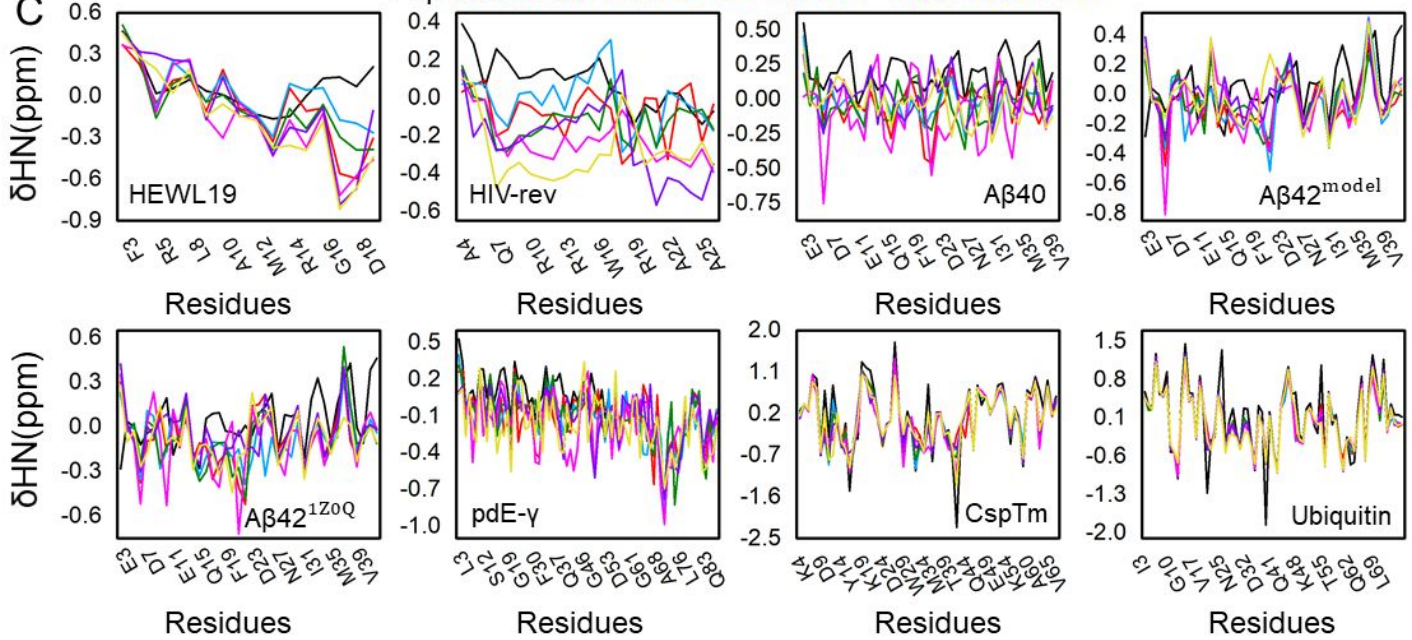

Residues 

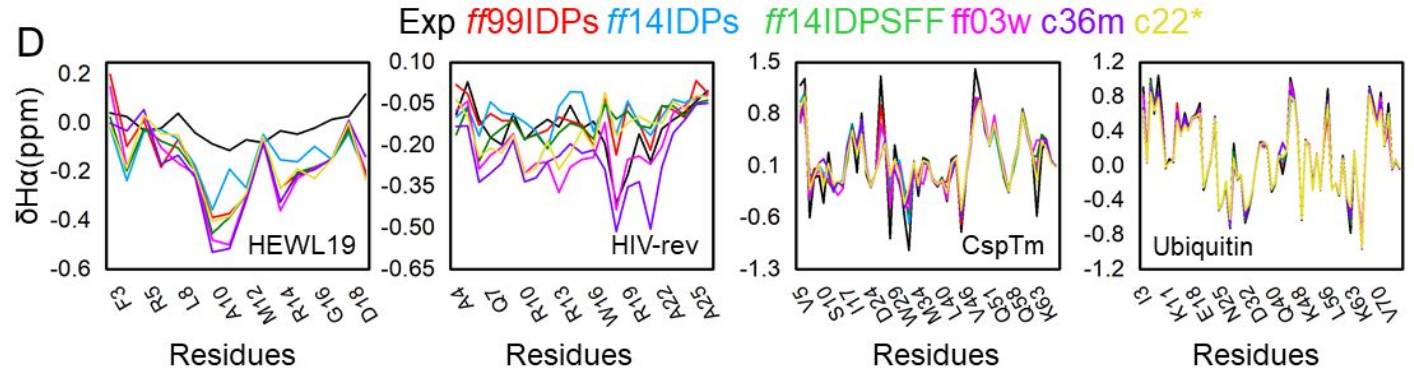

45 Figure S3. Comparison of secondary chemical shifts between MD simulations and

NMR experiments. (A) $\mathrm{C} \beta$; (B) $\mathrm{N}$; (C) $\mathrm{HN}$; (D) $\mathrm{H} \alpha$. 

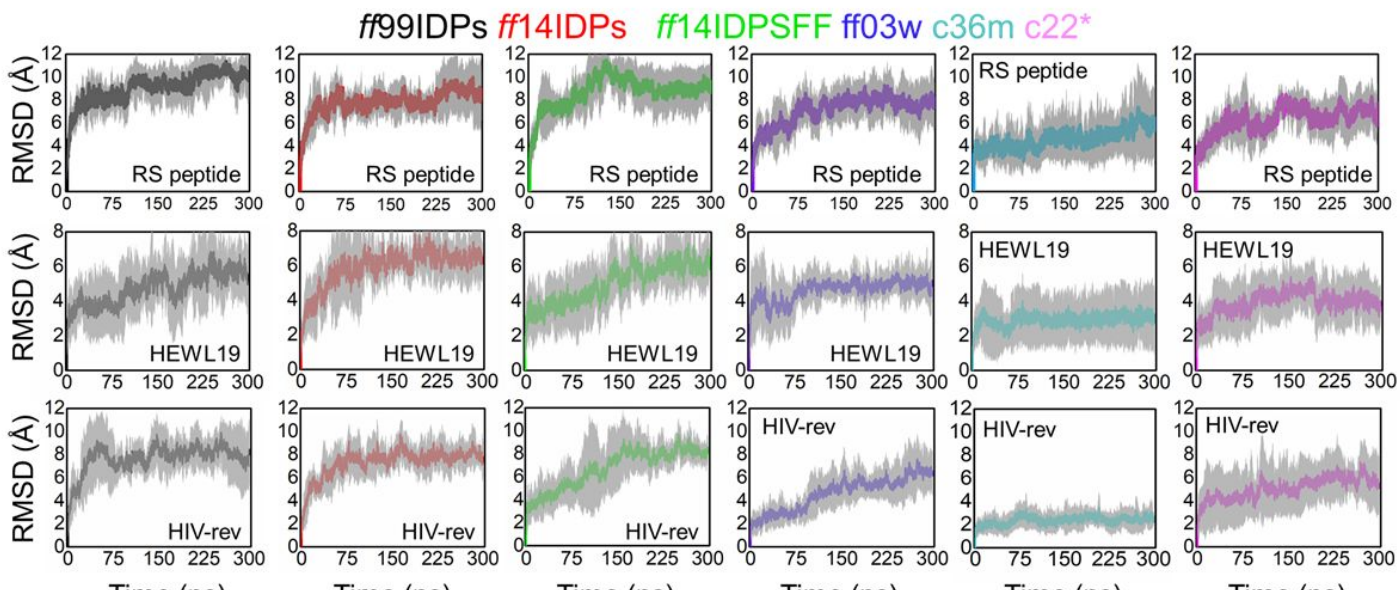

Time (ns)

Time (ns)

Time (ns)

Time (ns)

Time (ns)

ff99IDPs ff14IDPs ff14IDPSFF ff03w c36m c22*
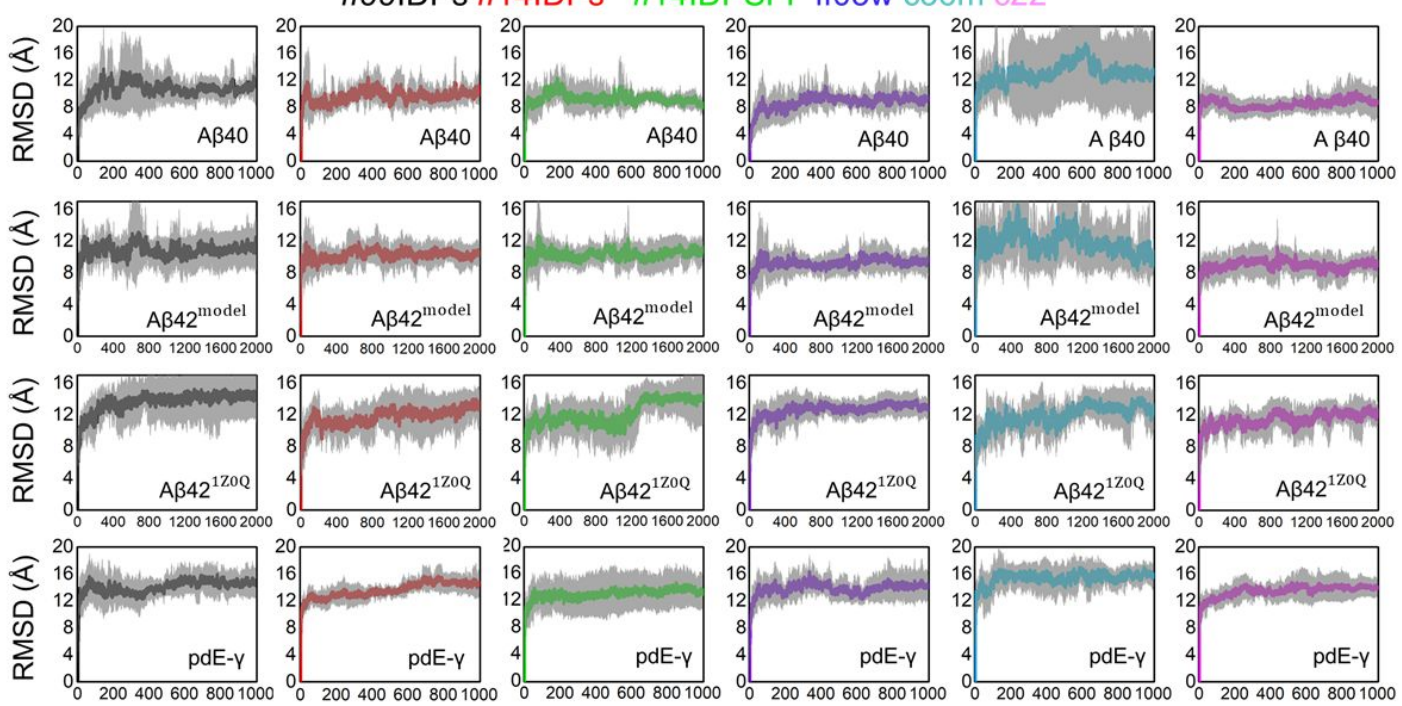

Time (ns)

Time (ns)

Time (ns)

Time (ns)

ff99IDPs ff14IDPs ff14IDPSFF ff03w c36m c22*
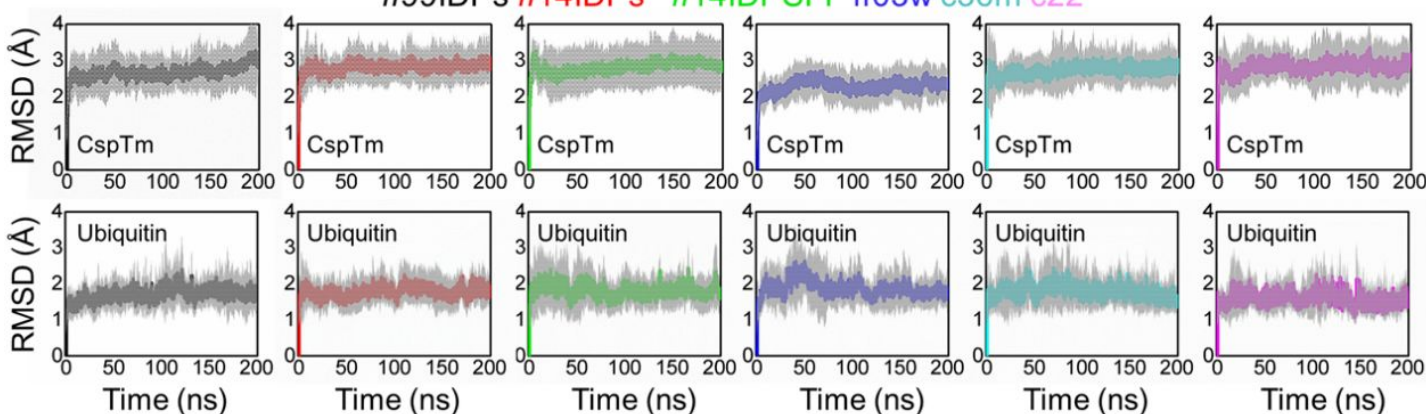

Figure S4. RMSD analyses of all the trajectories under the tested force fields. All of the reported rmsd values are calculated over the backbone atoms. The grey regions represent the error. 

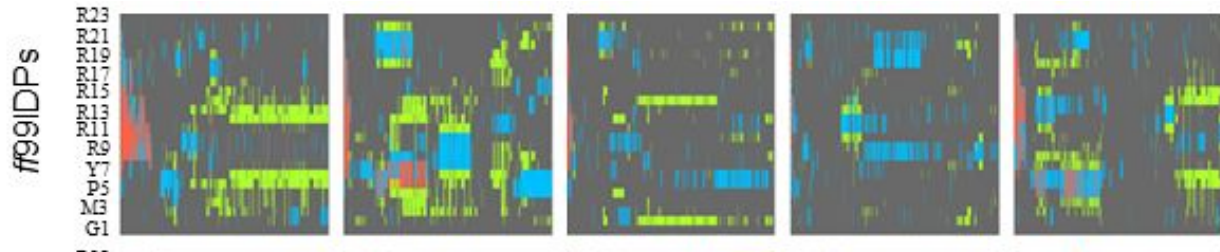

(A)
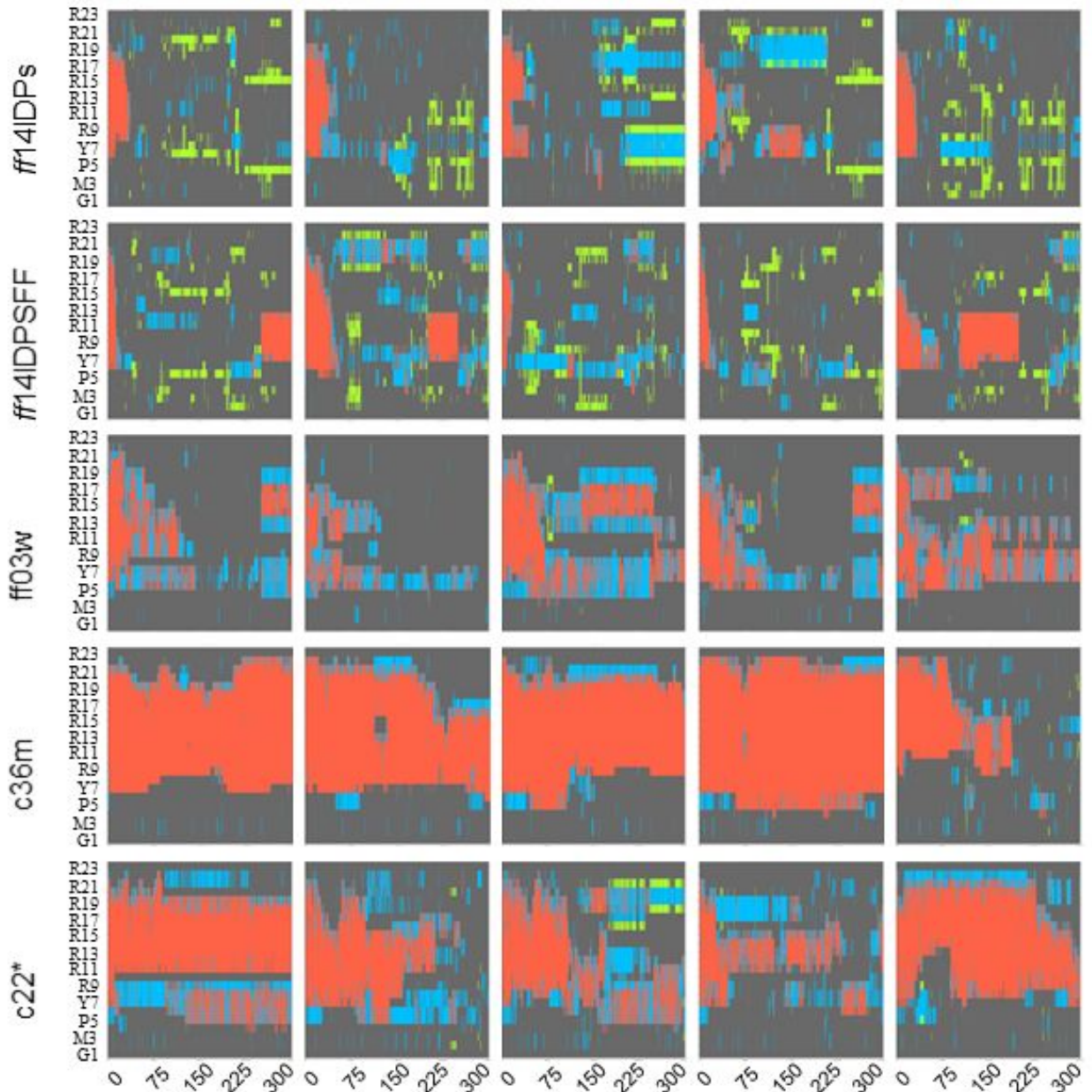

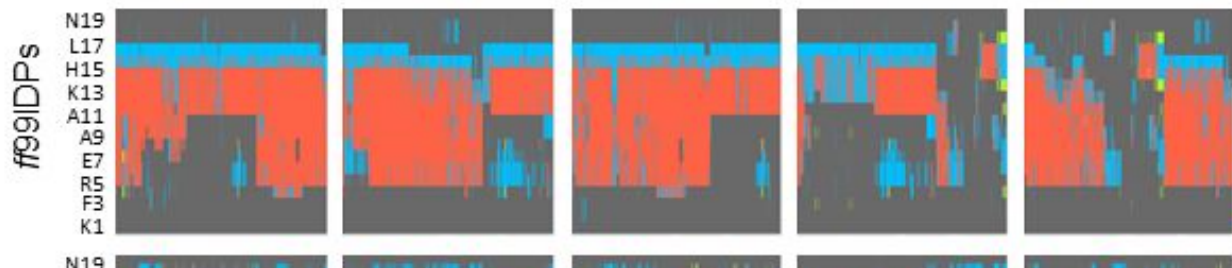

(B)
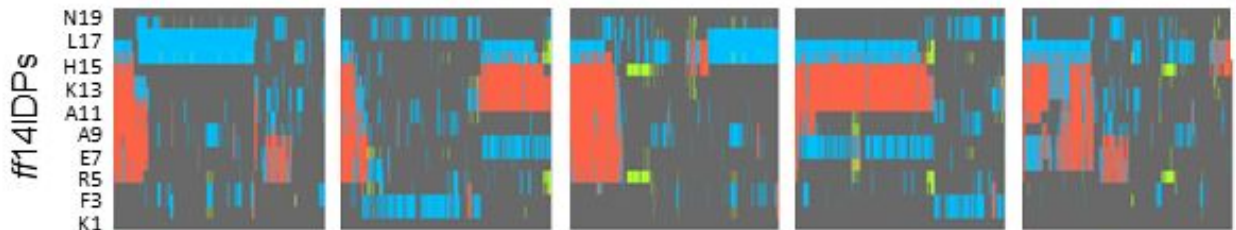

loop sheet

turn
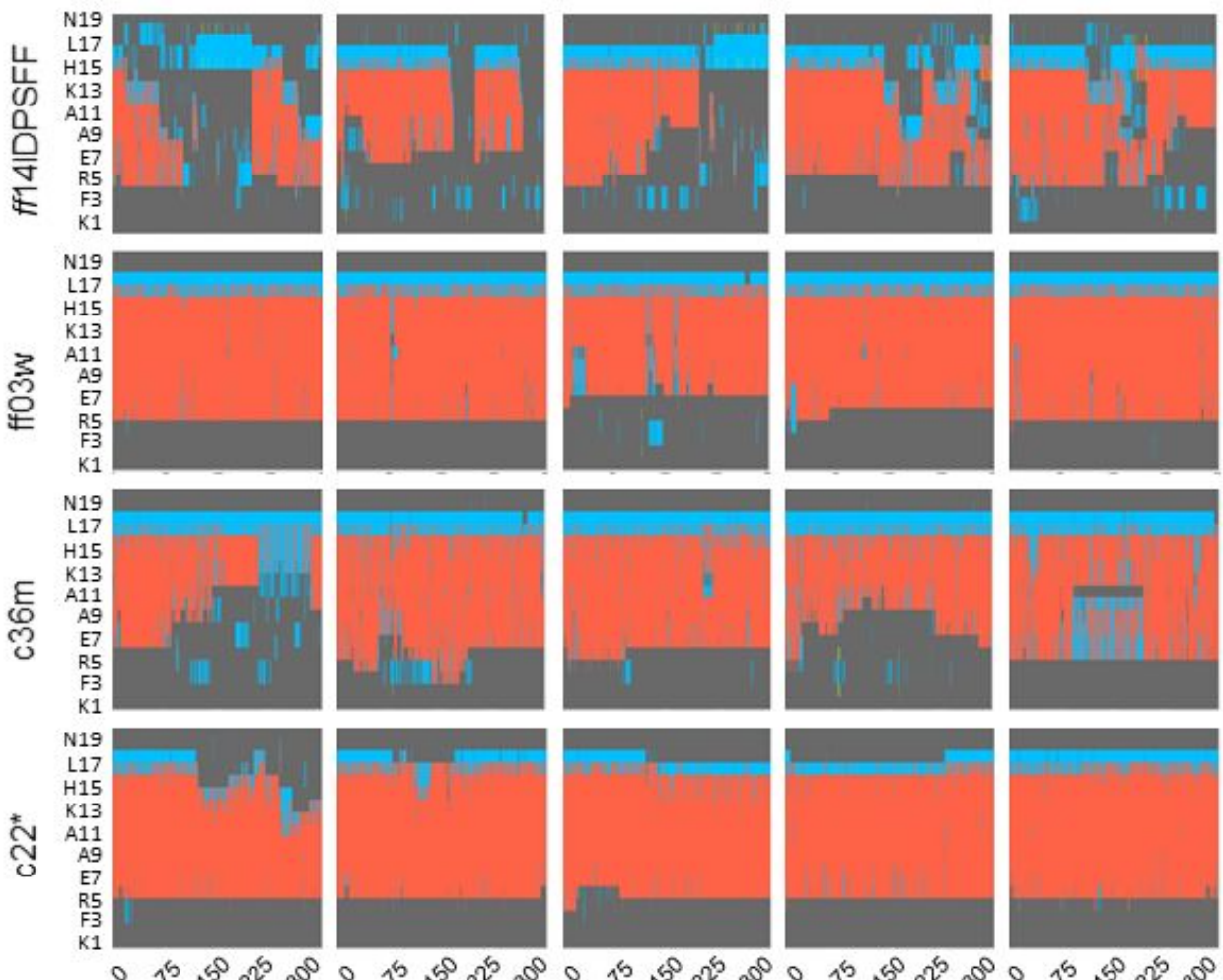

helix 

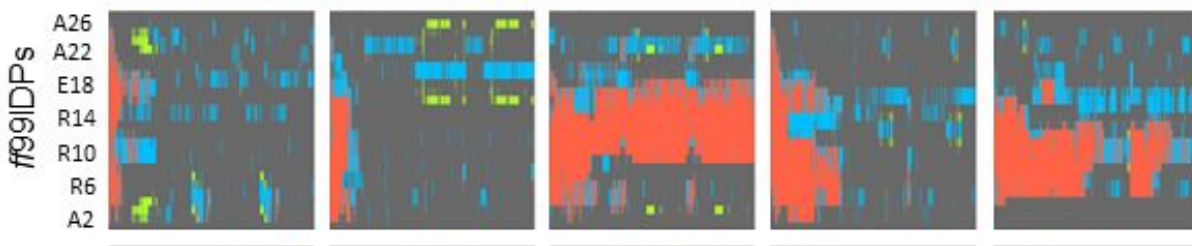

(C)
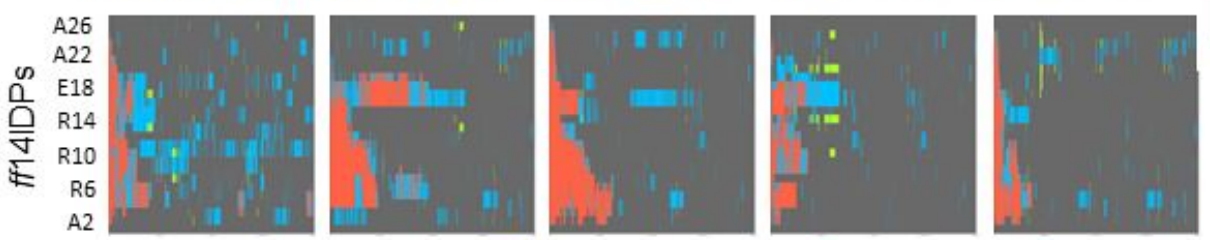

loop sheet

turn
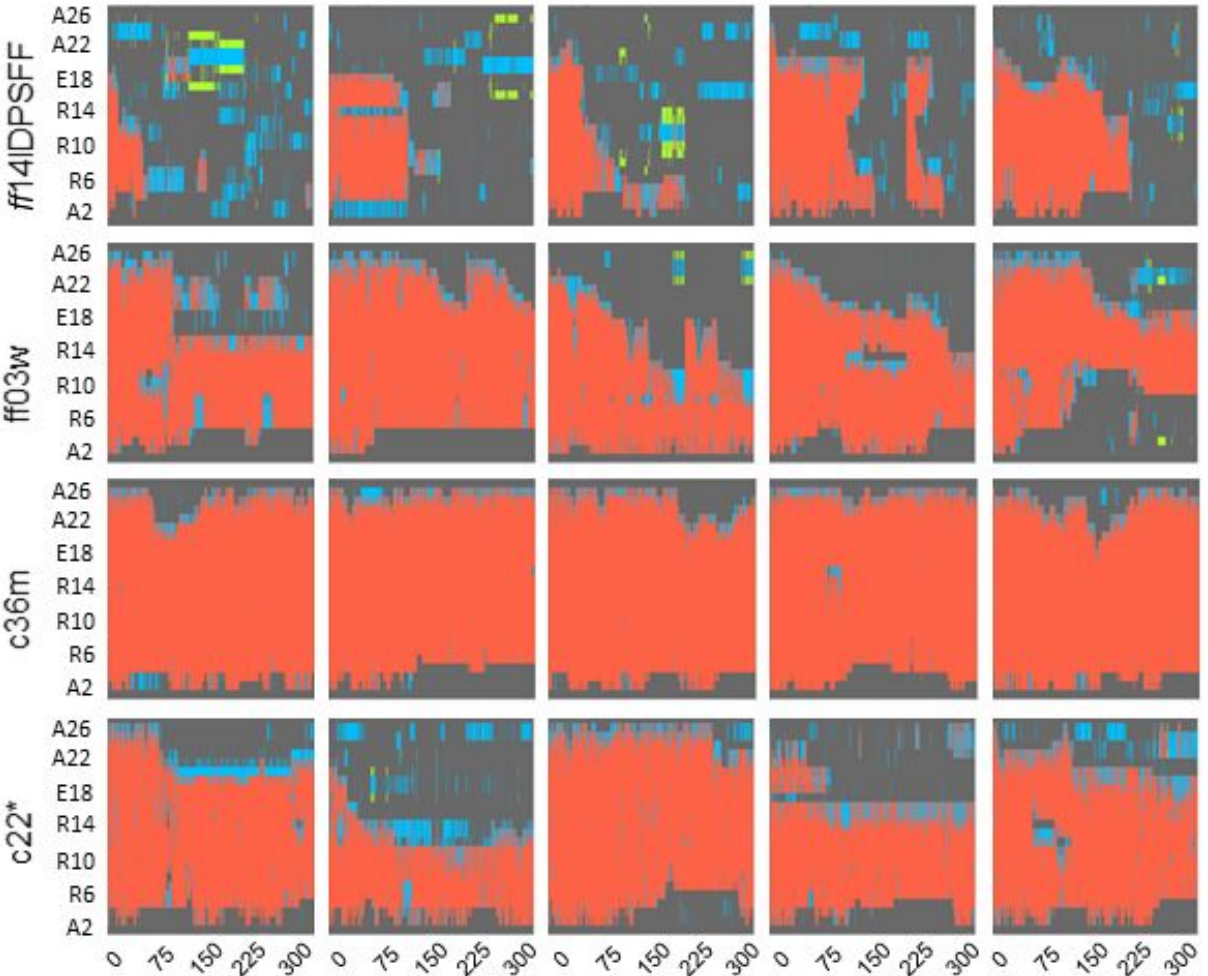

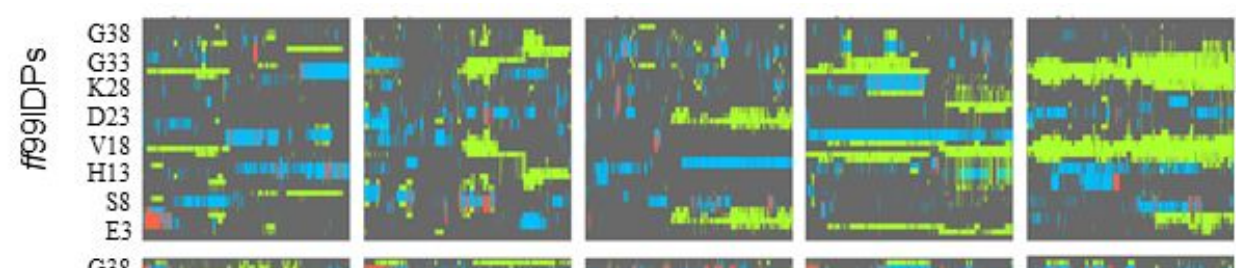

(D)
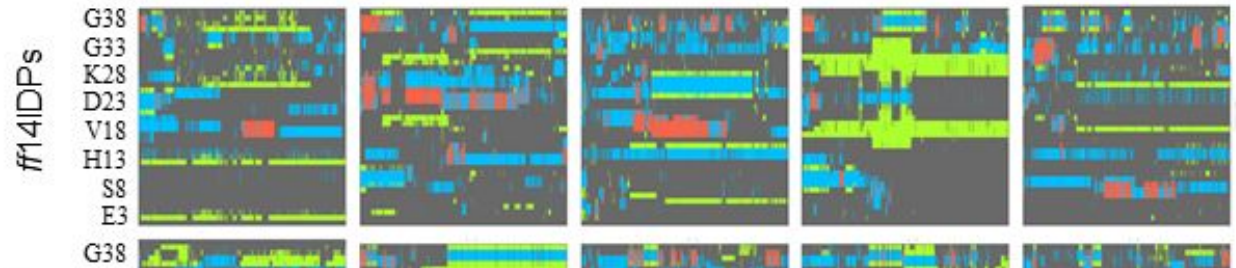

loop sheet turn
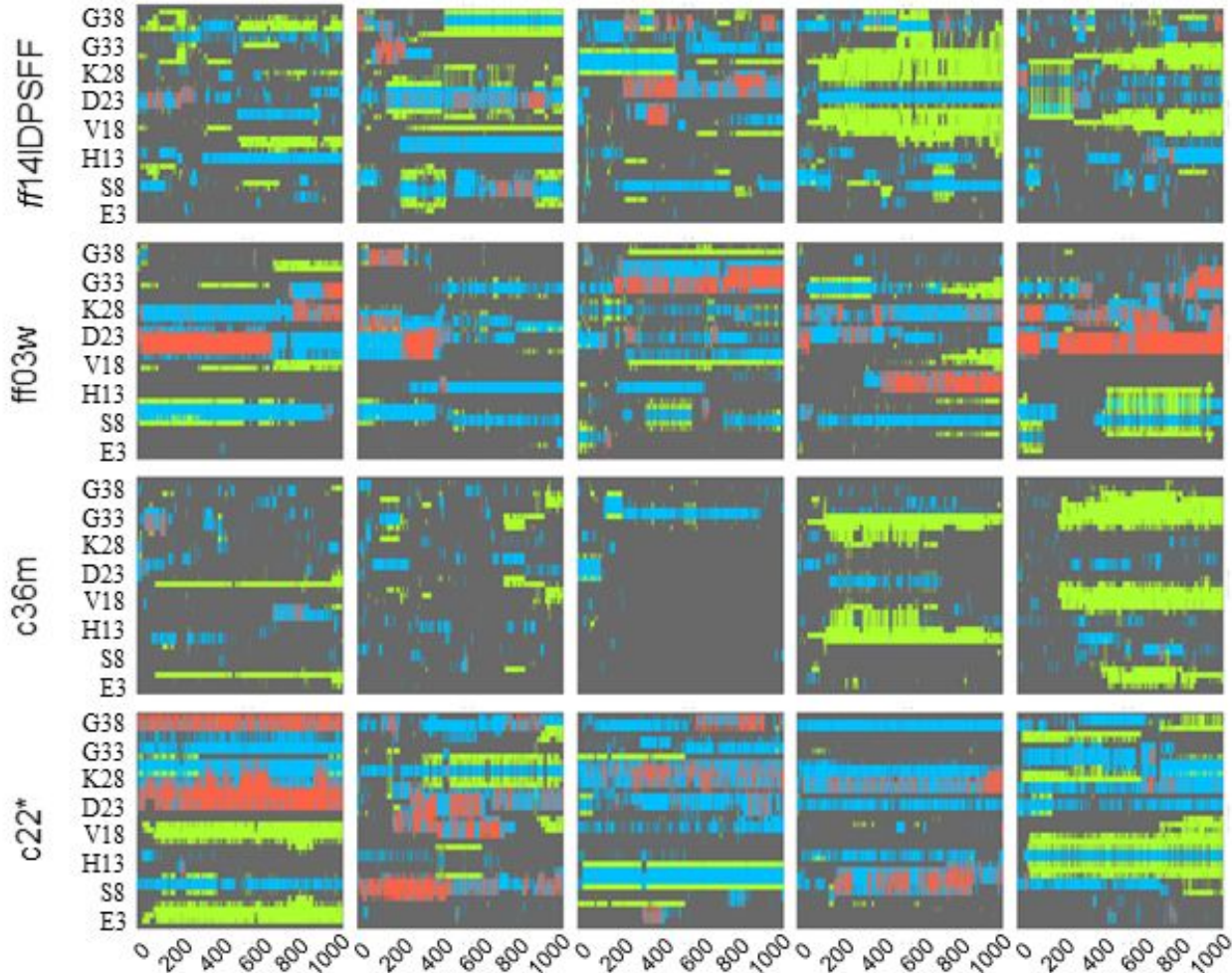

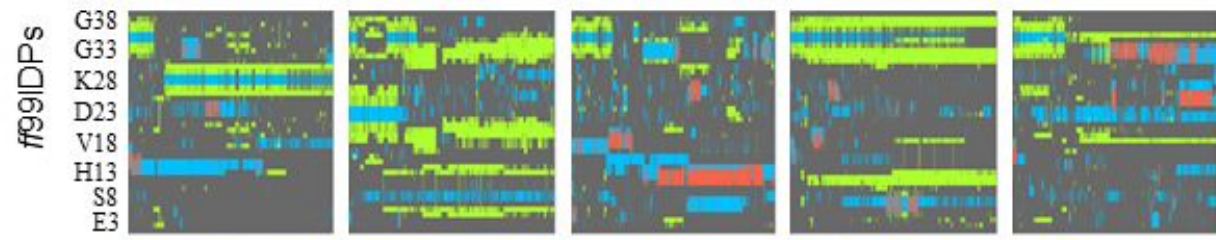

(E)
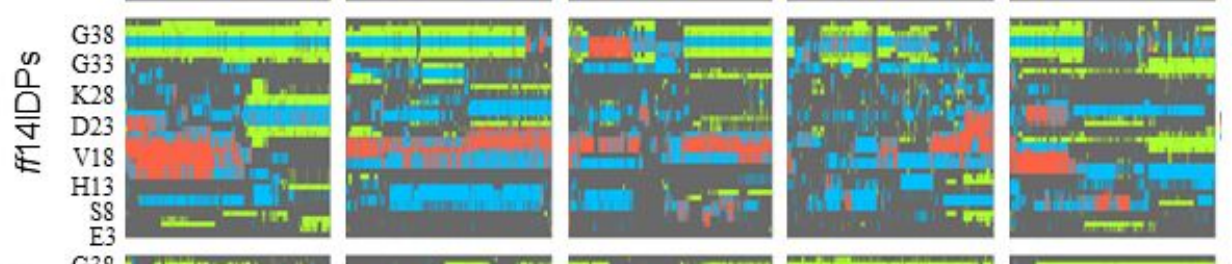

loop sheet

turn
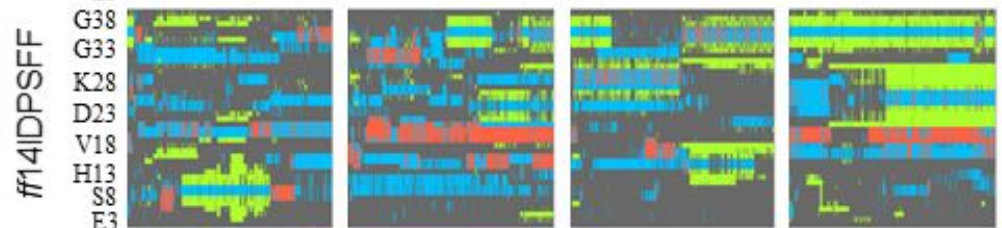

helix
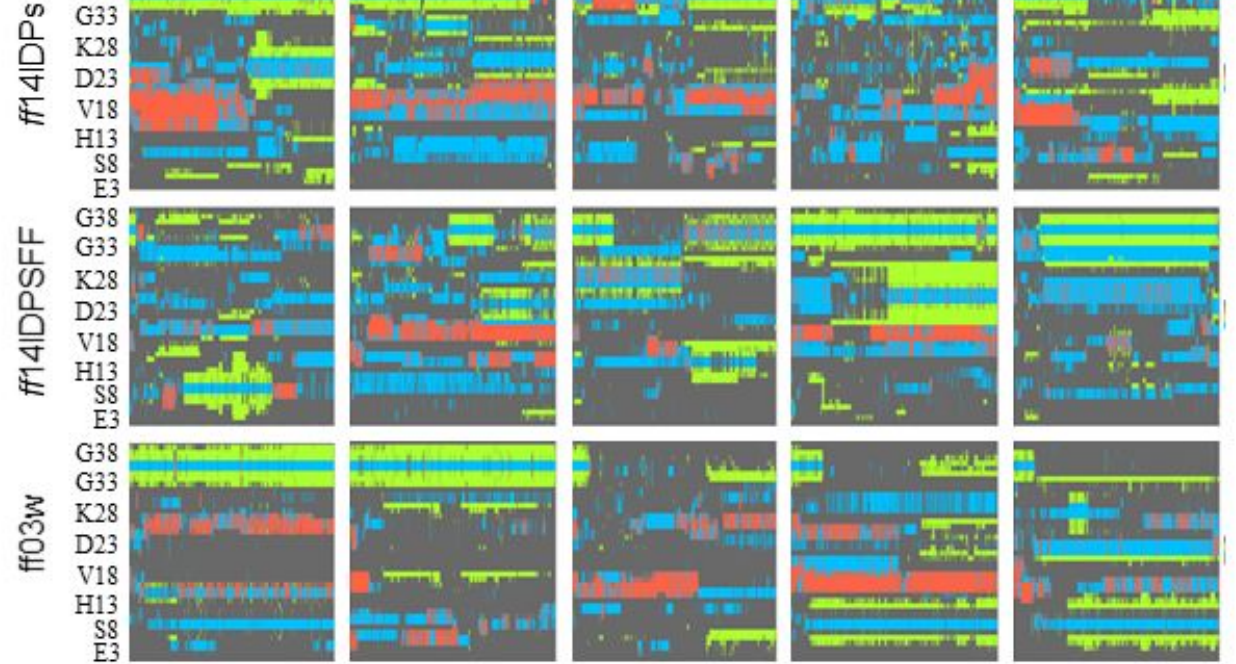

1.
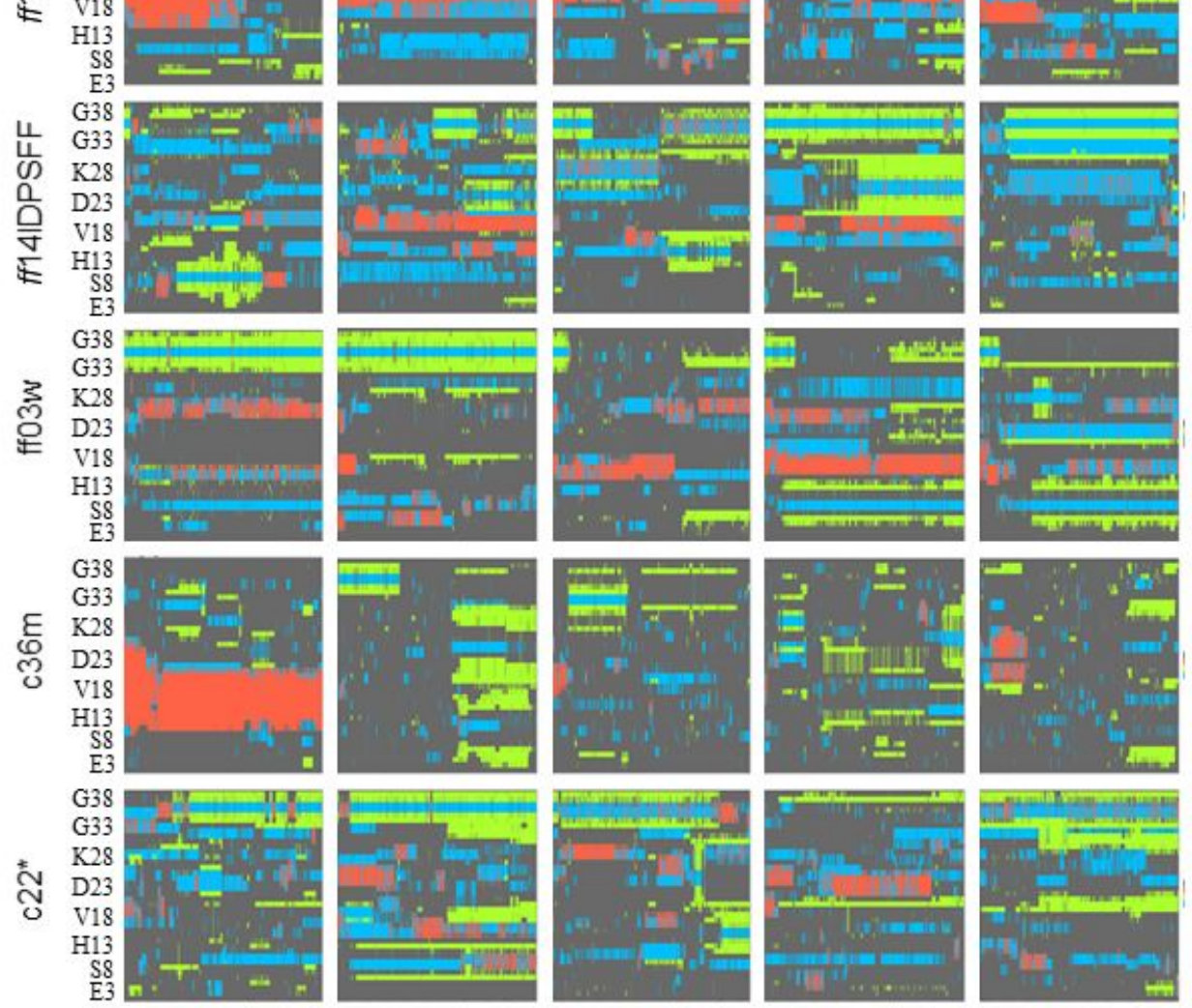

-

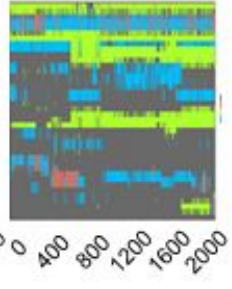



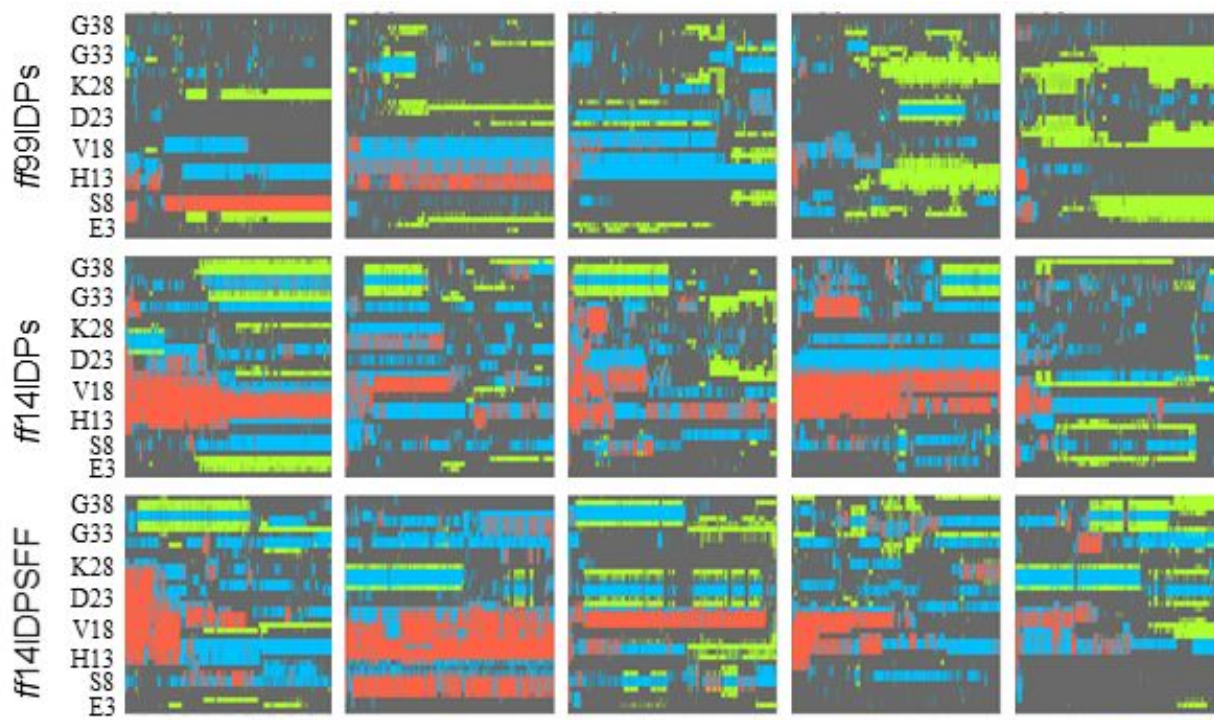

(F)
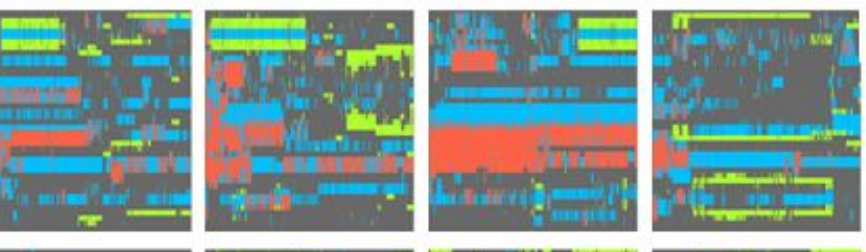

loop sheet

turn helix
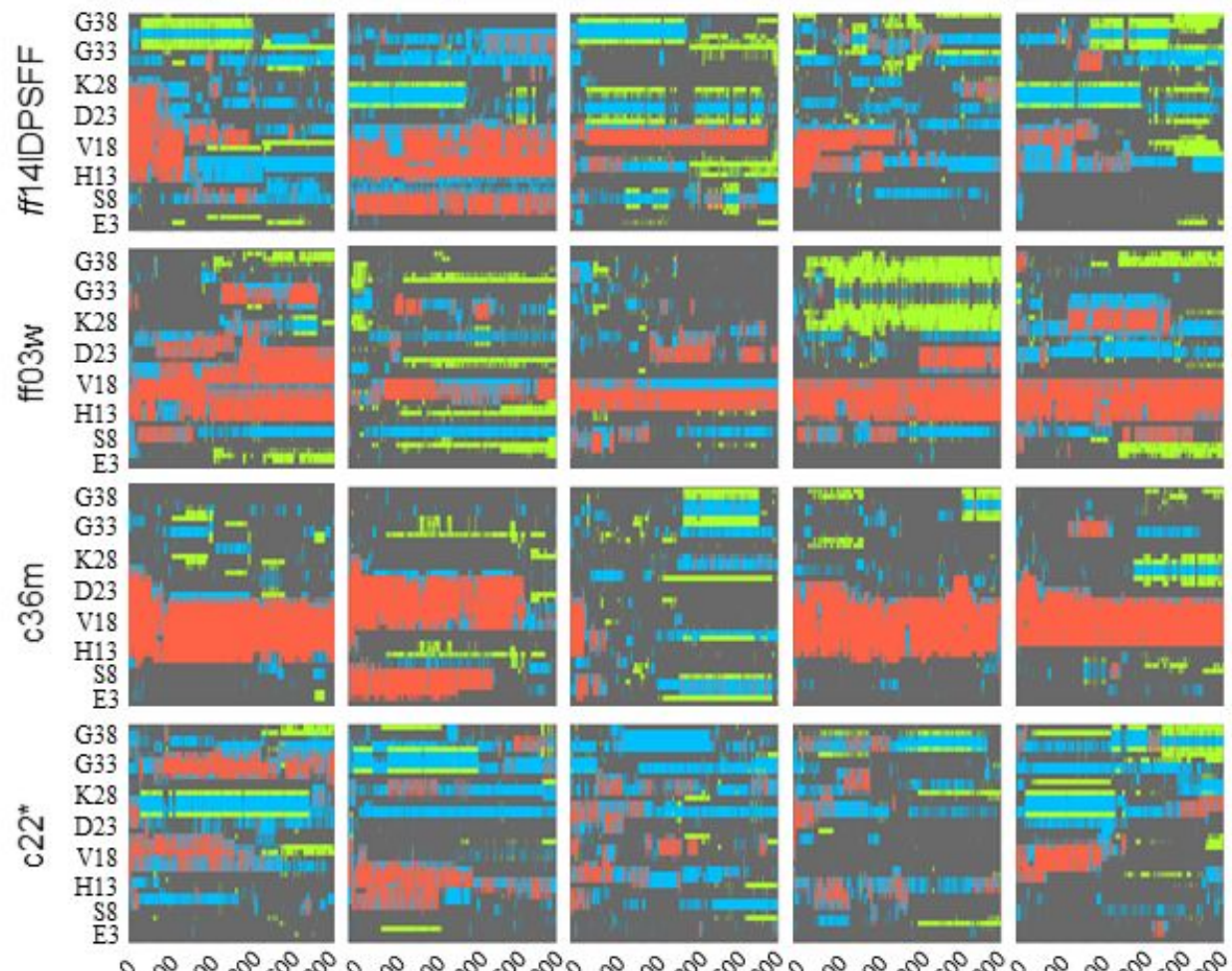

0 . 


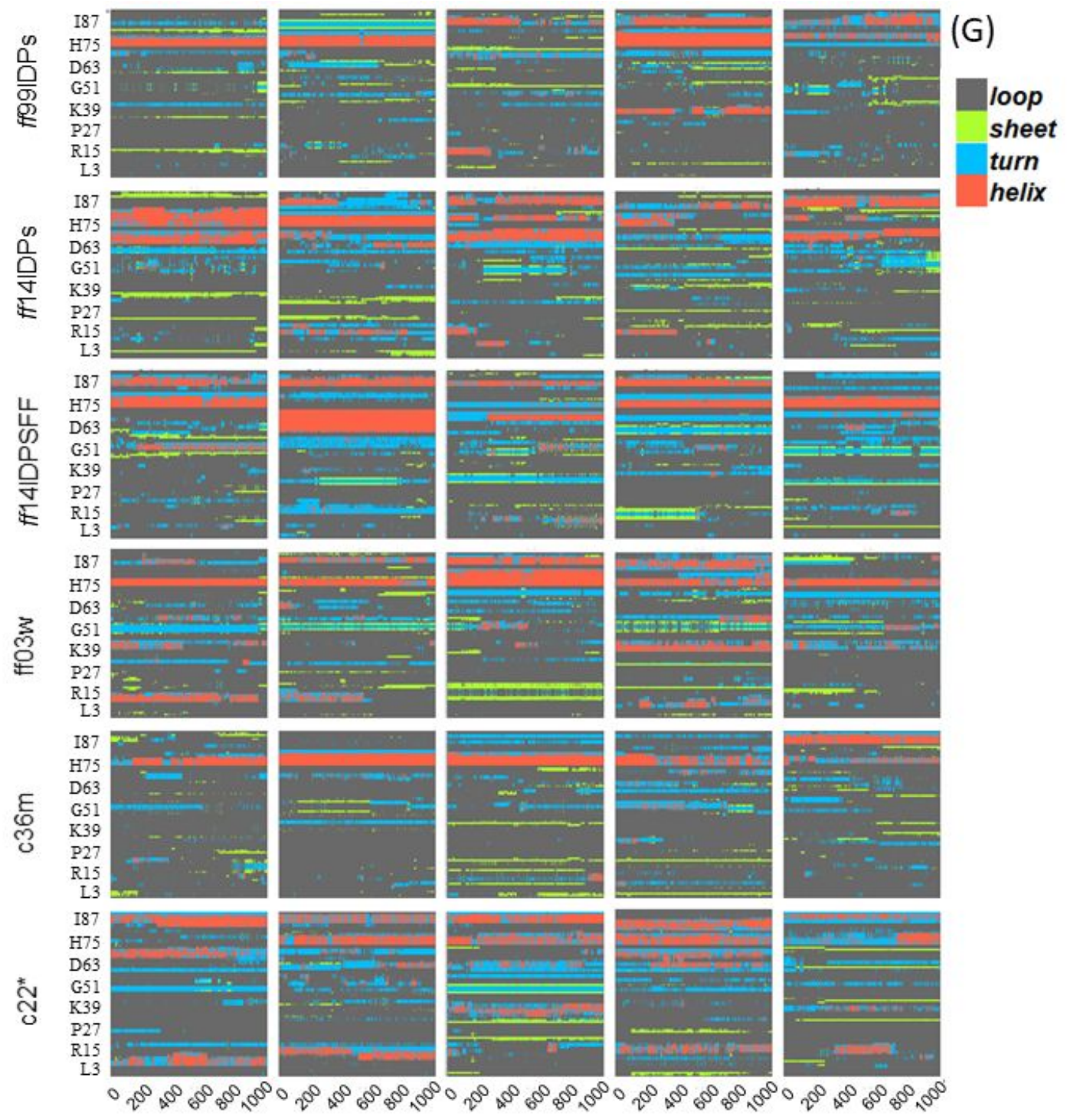




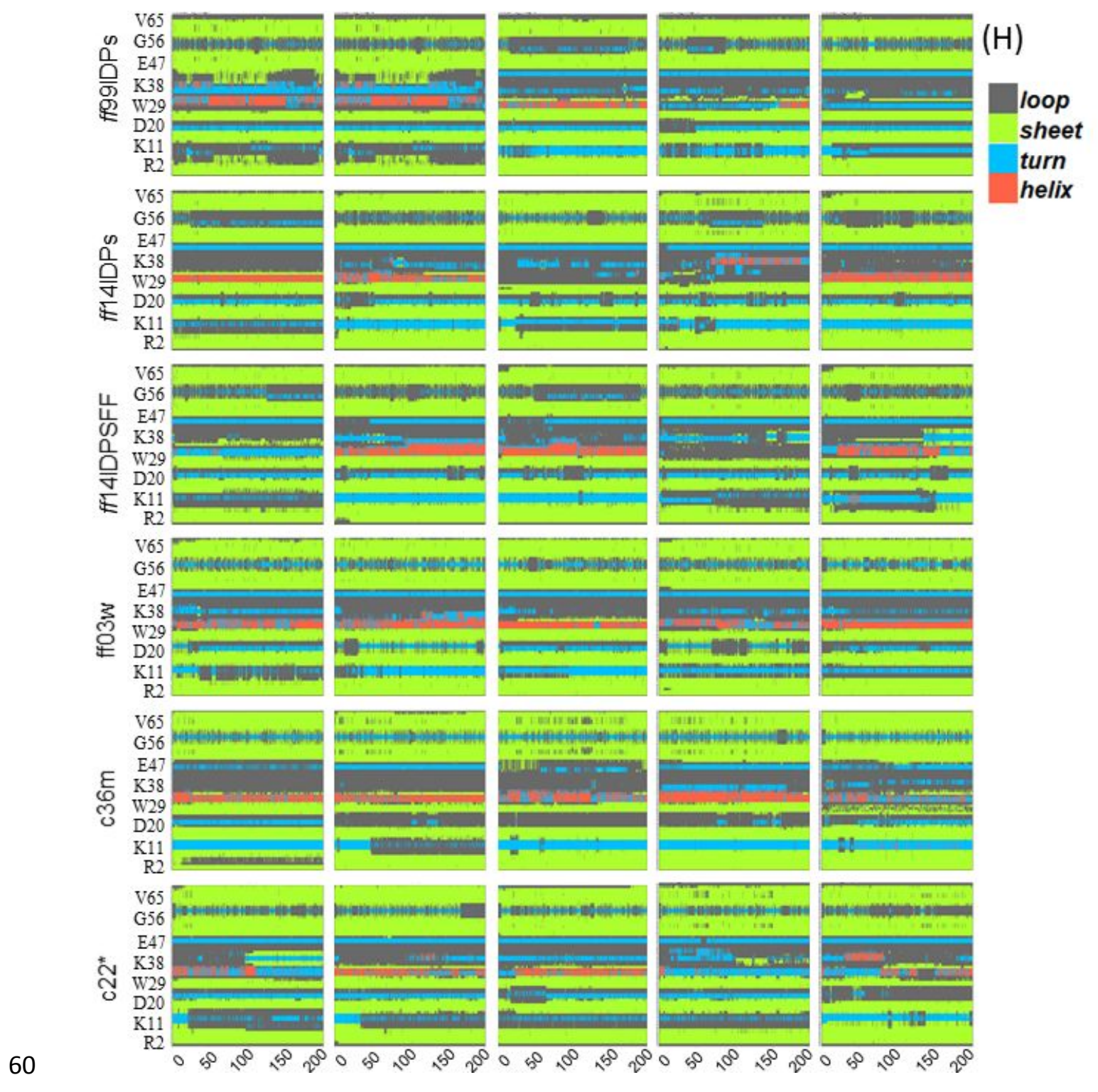




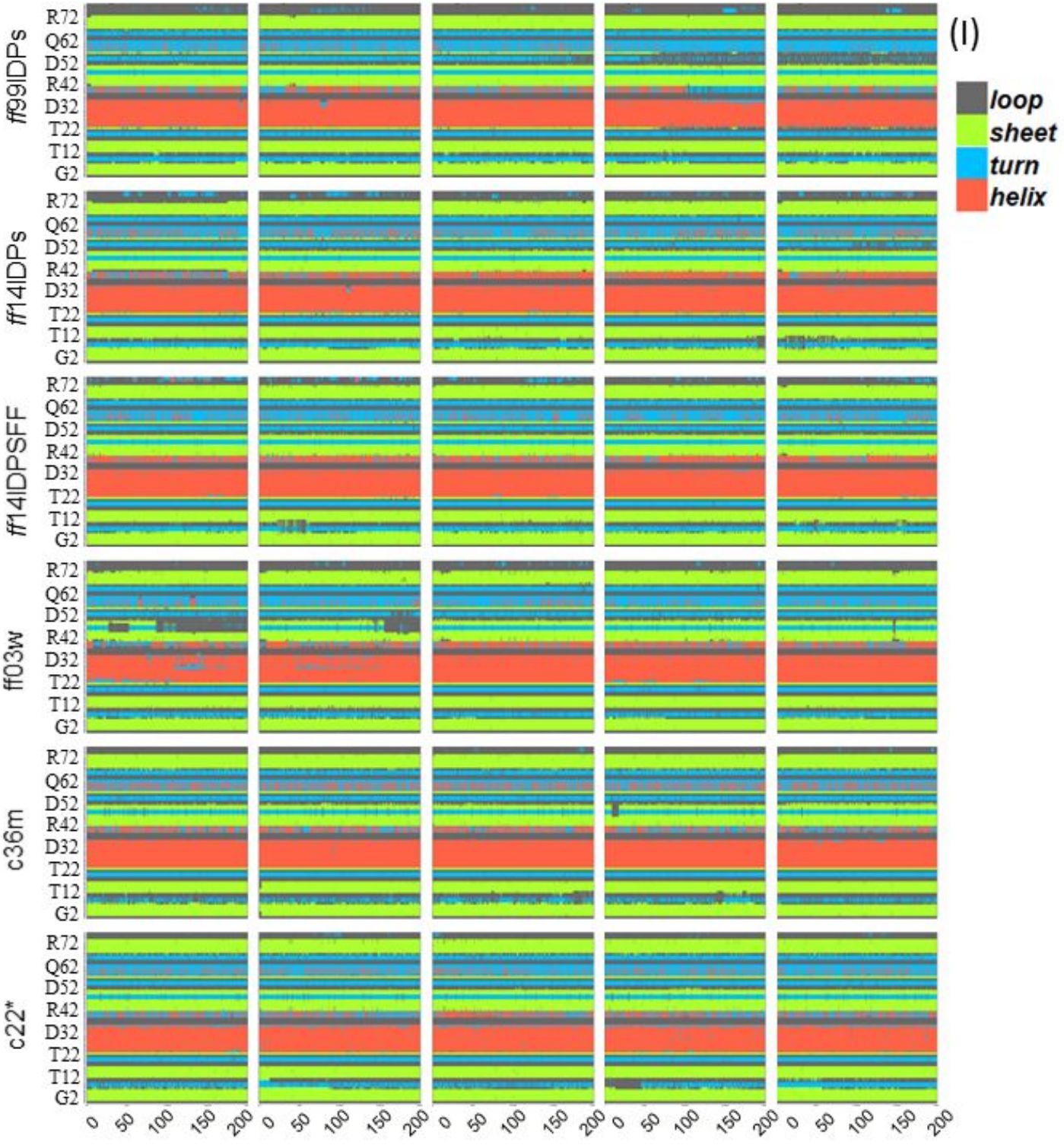

63 Figure S5. secondary structure propensity analysis of the trajectoreis. (A) RS-peptide; 64 (B) HEWL19; (C) HIV-rev; (D) A 340 ; (E) A $\beta 42^{\text {model } ; ~(F) ~ A ~} \beta 42^{1 Z 0 Q}$; (G) pdE- $\gamma$; (H) 65 CspTm; (I) Ubiqitin. Each tile (from left to right) represent single trajectory. 

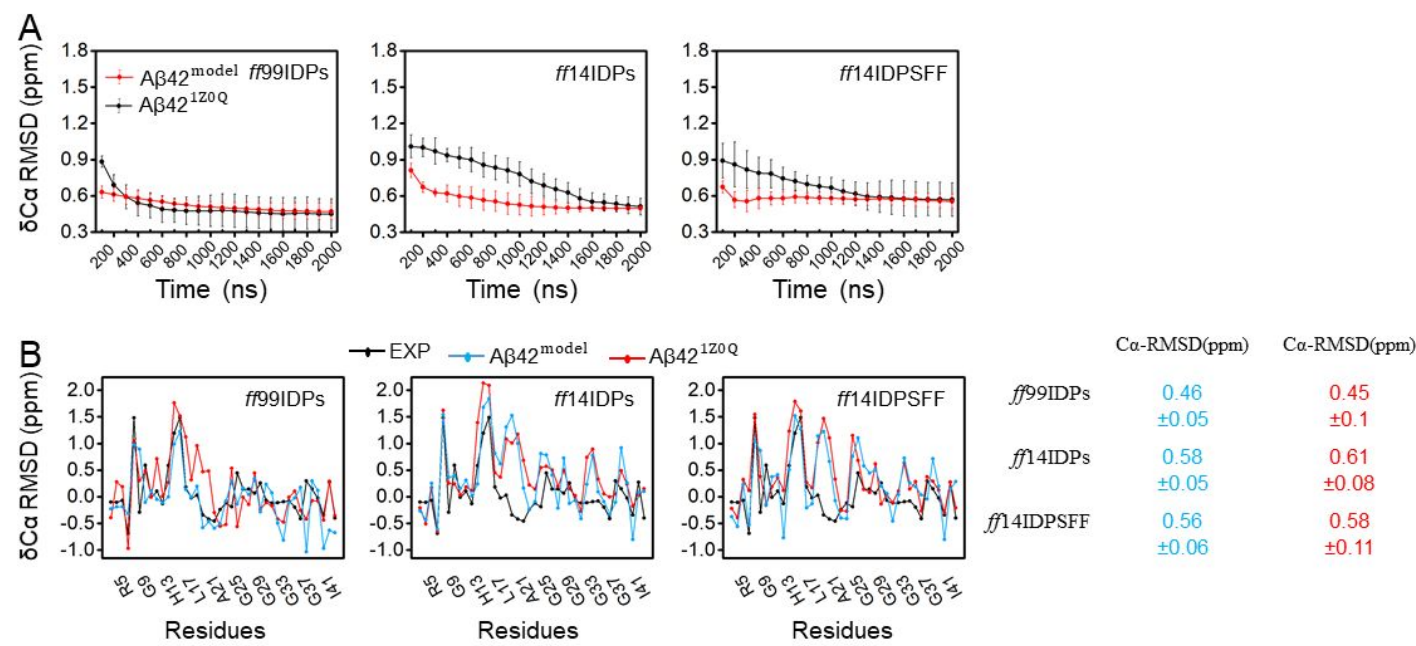

Figure S6. Calculated NMR observables in simulations of Ab40 starting from the PDB 68 structure and the extended structure. (A) Time-dependent changes in RMD of $\mathrm{C} \alpha$ 69 chemical shifts. (B) Comparison of Predicted $\mathrm{C} \alpha$ measurements with experiment 70 between $\mathrm{A} \beta 42^{\text {model }}$ and $\mathrm{A} \beta 42^{1 \mathrm{IZOQ}}$.

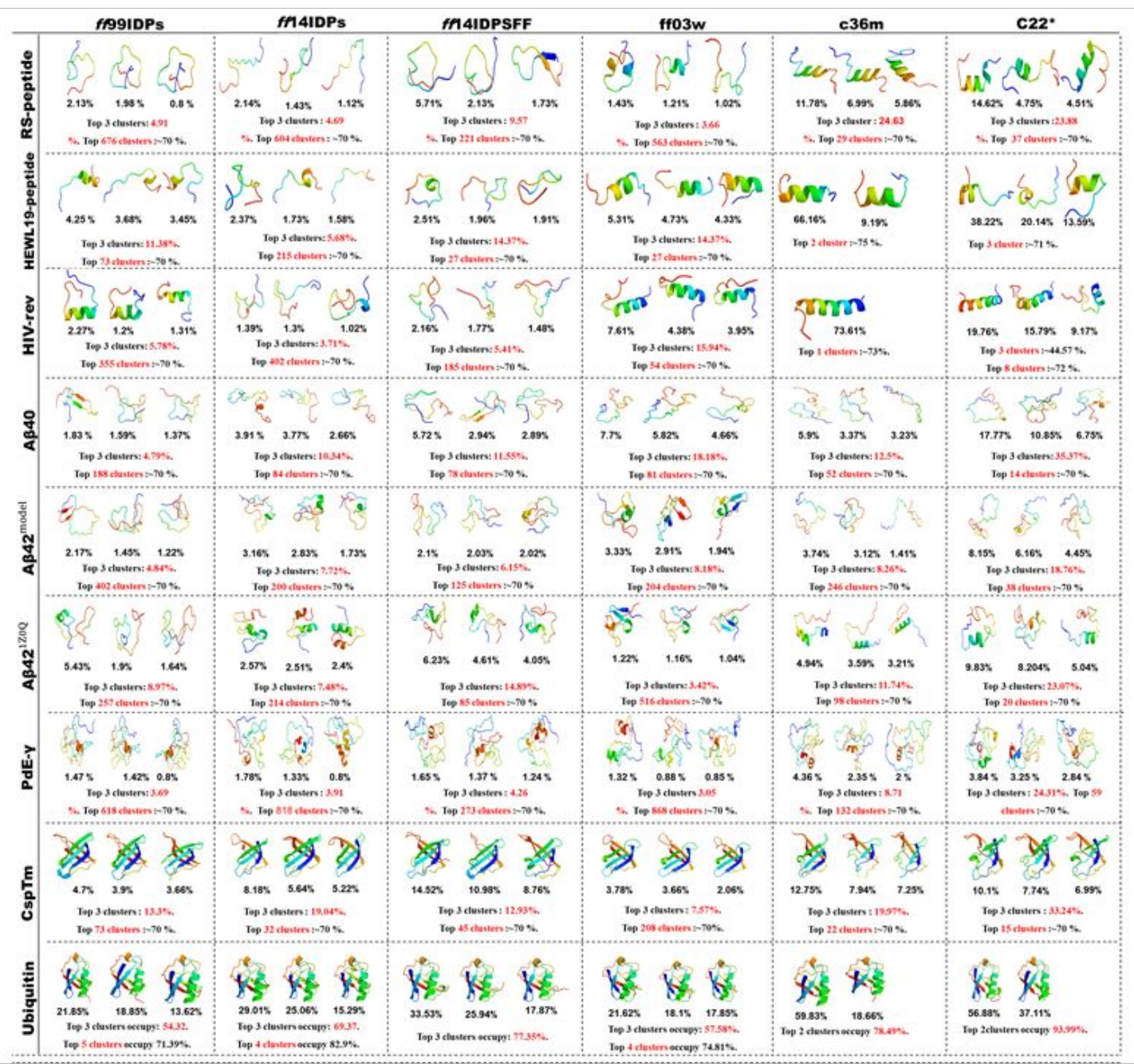


73 Figure S7. Cluster analyses. Top 3 clusters were taken and analysed for all the proteins

74 reproduced under the tested force fields. The numbers in percent represent the 75 occupancy out of entire ensembles. 